\title{
CAN WE TRUST WHAT WE SEE ONLINE?
}

Dr Elvira Perez Vallejos

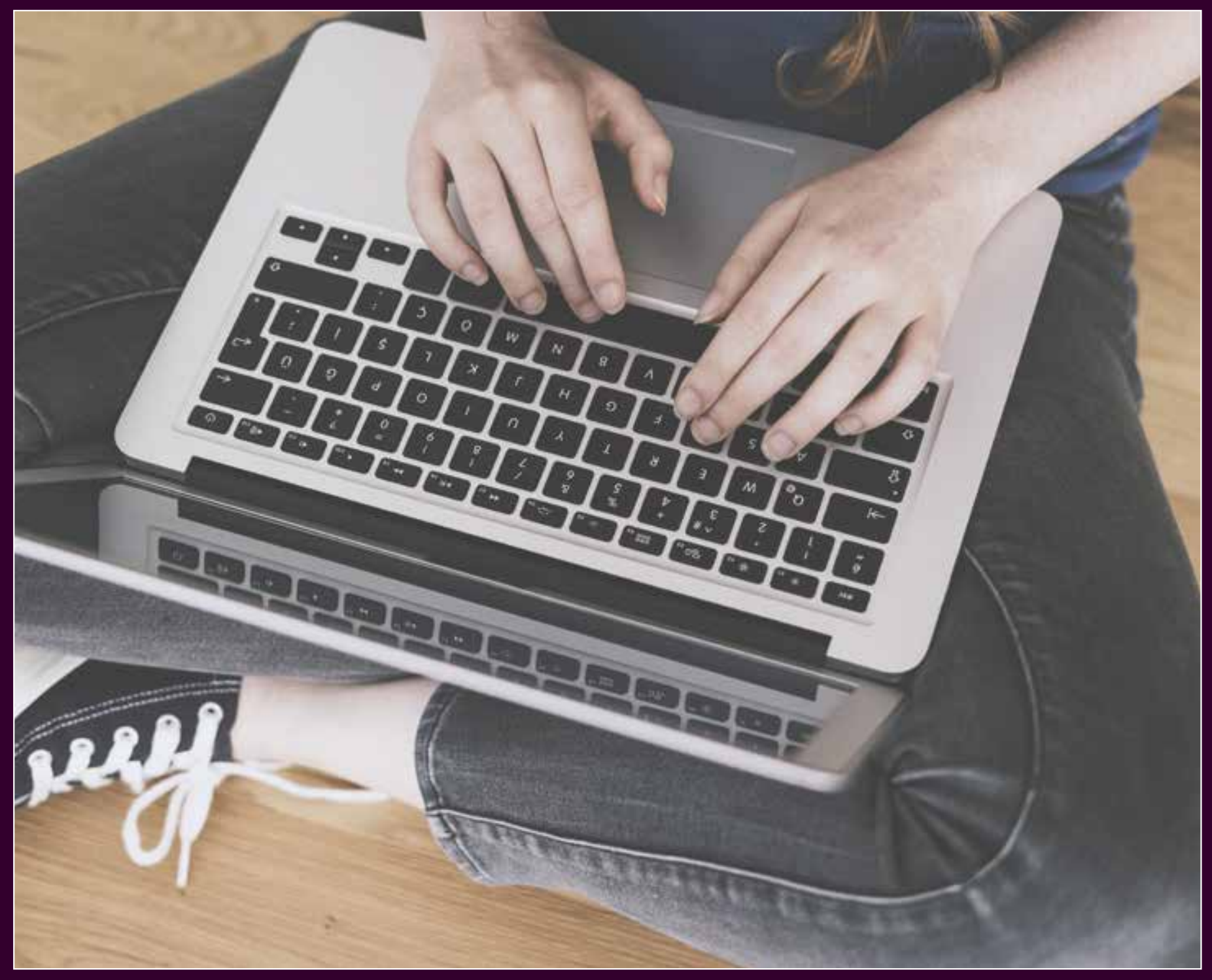




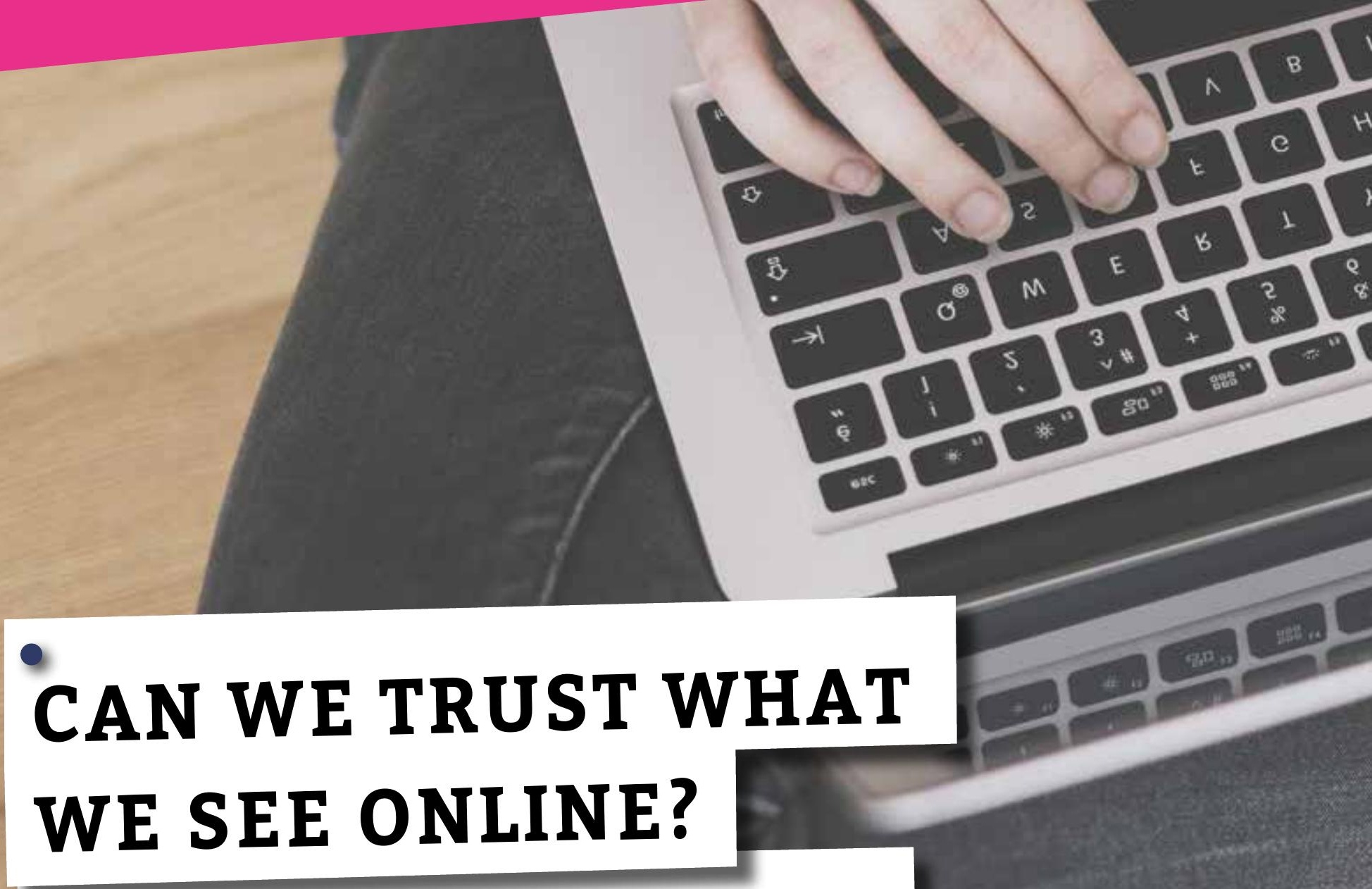

WEBSITES USE ALGORITHMS TO RECOMMEND MUSIC, TV AND FILMS THAT YOU'LL ENJOY. BUT THEY COULD ALSO BE MANIPULATING US AND HIDING THE TRUTH. DR ELVIRA PEREZ VALLEJOS FROM THE UNIVERSITY OF NOTTINGHAM IS EXAMINING HOW TECHNOLOGY CAN BE MADE MORE TRUSTWORTHY

\section{IMAGINE THIS}

1. The news stories you see on social media are placed there by computer algorithms. Humans may be able to manipulate algorithms to spread negative stories about politicians they don't like. In turn, this may put people off voting for them.

2. When you search a travel-booking website for hotels, you'll be shown a list of top deals. But some hotels pay booking websites to appear higher up the rankings. In other words, you may not see the very best deals.

Imagine if youth juries - groups of 16 to 25 -yearolds - could help governments bring in new rules to stop these types of behaviour!

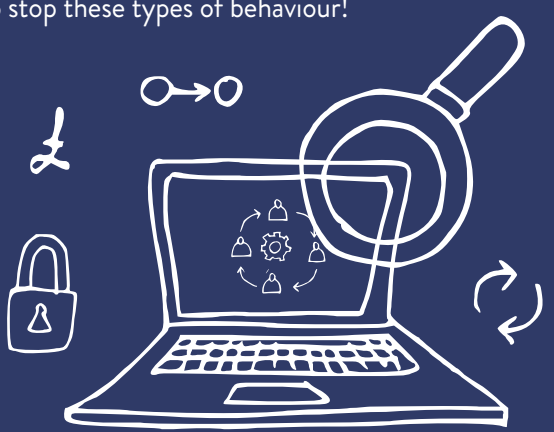

Think back to the last time you listened to music on your phone. Your app probably suggested more artists you might enjoy, based on what you've listened to before. The same kind of recommendations are everywhere, from streaming services suggesting new TV shows to stores offering more things to buy.

How do these recommendations work? They're constructed using algorithms - sets of instructions that tell computers what to do. Algorithms can tailor recommendations to your personal taste by using sophisticated artificial intelligence (AI) software. The recommendations aren't always perfect, but the machines learn and get more accurate over time.

Making these algorithms trustworthy and fair is the goal of Dr Elvira Perez Vallejos, Associate Professor of Digital Technology and Mental Health at the University of Nottingham. Elvira is involved in a project called ReEnTrust: Rebuilding and Enhancing Trust in Algorithms.

ARE ALGORITHMS A GOOD THING?

If they help you find more good music, movies and TV, then yes! But they're also used to decide which stories we see on social media. Those stories might be biased in favour of a certain company or individual, or they might even be fake news! How can we tell if algorithms have been designed to manipulate us? How do we know that the information we see is accurate and fair? "If you aren't exposed to challenging views that contradict your own, you end up with a 'bubble effect' that prevents you from being exposed to other opinions," says Elvira.

\section{CAN ALGORITHMS "SPY" ON US?}

New technologies like Al and machine learning are harnessing more data about us than ever before. We agree to give away this data when we accept the terms and conditions after downloading an app. It's not surprising that few people read these terms and conditions because they're so long! According to Elvira, the danger is that the data will be used to predict your behaviour - and not always in a good way. "It could be used to manipulate people's opinions, let them only apply for specific jobs or prevent them being able to access health insurance," she explains. 


\section{ABOUT DIGITAL TECHNOLOGY}

\section{AND MENTAL HEALTH}

Can using your phone affect your mental health? It's often said that too much screen time is a bad thing, and some scientific research suggests that's true. The precise nature of what you see on social media can also change how you feel. But on the flipside, phones and social media have positive benefits. Part of Elvira's research involves looking at whether the design of online platforms can affect your state of mind - for better or worse.

WHY DO WE SPEND SO MUCH TIME ON SOCIAL MEDIA?

Partly because we enjoy it! But there's no doubt that social media and other apps are designed to make us want to use them for longer. The choice of colours, notifications, and "likes" all make social media a habitforming activity it's hard for many people to break. A small number of people may even be diagnosed with social media addiction by their doctors. Elvira is interested in looking into designs that give users more control over their use of the internet.

WHAT ARE THE POSSIBLE NEGATIVE EFFECTS?

Teenagers who are heavy users of digital devices are twice as likely to show symptoms of ADHD (attention-deficit/hyperactivity disorder), according to a study in California. Another recent study in the US looked at the link between social media use and depression in adults aged 19-32. It found that the more frequently they checked social media, the more likely they were to be depressed. In the UK, a YouGov survey found that $46 \%$ of $16-25$ year olds said they felt inadequate when they compared their lives with those of others on Instagram, Facebook and Twitter. And 57\% said that using social media made them feel "overwhelming pressure" to succeed. There's also evidence that the time teenagers spend socialising in person - at parties, sports and other events - is 16 minutes less per day than it was 10 years ago.

DOES DIGITAL TECHNOLOGY HAVE POSITIVE BENEFITS?

Yes. Online communities can be a good way of talking to other people about mental health. You can access people who can give you support instantly through your phone or computer. Depressed people might not feel up to leaving the house, but they can still send messages. According to the charity Mind, four in five people find it useful to talk about mental health and the internet gives us the opportunity of instantly doing just that. It's also likely that social media doesn't affect everyone in the same way. Just as not everyone who plays poker becomes addicted to gambling, social media may not cause you any ill effects.

IS THERE ANY CLEAR-CUT ADVICE

ON HOW WE SHOULD USE

TECHNOLOGY?

In a word, no. According to Elvira, not enough scientific evidence has been gathered on the effects of the internet on our lives. That's why, together with her colleagues, she's developing a way of measuring online wellbeing. It will look at how people feel before and after using the internet for a set period of time.

\section{OPPORIUNITIES IN DIGITAL TECHNOLOGY AND MENTAL HEALTH}

- Elvira works in a multidisciplinary field, encompassing both digital technology and mental health. - With thousands of new jobs predicted each year, there's never been a better time to start a career in digital technology. In the UK, the average salary in this sector is $£ 37,500$ compared to a national average of $£ 28,000$.

- The UK government runs an apprenticeship scheme in digital technology, suitable for students aged 16 and over.

- There are loads of summer camps that focus on digital technology. Check out TechCamp, Fire Tech Camp and iD Tech.

- If you're interested in doing research in psychology or mental health, check out the Careers in Psychology or the Psychology School Guide websites.

- The average salary for a research psychologist in the UK is $£ 40,000$

- Voluntary work or work experience can help when you apply for a psychology degree. Childline, Mind, Rethink Mental IIIness and many charities all offer voluntary work. The NHS offers work experience placements.

- Be a part of Elvira's research project by becoming a member of a "youth jury": https://reentrust.org/2019/04/05/reentrust-are-recruitingfor-citizen-juries/ 


\section{ASK DR ELVIRA PEREZ VALLEJOS}

WHAT DID YOU WANT TO BE WHEN YOU WERE YOUNGER?

I'm from Spain and when I first read the word "psychology", I didn't understand why it had a " $p$ ". I was intrigued. When I found out that it was the study of the human mind, I thought that was amazing. From then on, I wanted to be a psychologist and I haven't changed my mind! In particular, I'm fascinated by language. Language is such a complex activity for the brain - both to produce language and to understand speech. I'm very interested in how people describe situations, and how their opinions change. It's a fascinating topic.

WHAT SORT OF STUDENT

WERE YOU AT SCHOOL?

I was very responsible when it came to schoolwork. I remember that when I got home, the first thing l'd do was my homework so that it was out of the way. I never considered myself to be a clever person but I worked hard. I remember thinking that in a class of, say, 30 people, there'd be three or four who were naturally clever. They seemed to remember things they'd read, unlike me. I'd have to read something 10 times to remember and understand what it was about! I struggled with mathematics too, but I persevered. It was a great feeling to think: "Wow - I understand that now!", and that's what kept me moving forward.

\section{WHAT QUALITIES DO YOU}

NEED TO WORK IN RESEARCH?

Nowadays, multidisciplinary research teams are valued. But that is challenging because you need to work with people who have different academic backgrounds. For example, I'm a psychologist and I work with computer scientists. That's a different field, with a terminology and culture of its own. In order to succeed, you have to build resilience and relationships. It's not just about being an academic. You have to develop interpersonal skills to help you navigate the uncertainty of not knowing exactly what you're doing until the moment when everything clicks. It's a very satisfying moment but you have to build strength and resilience to get there. Sometimes the academic world isn't as gentle as it should be and sometimes you make mistakes. But don't be afraid of failure. In an academic career, producing amazing work is about trying again and again.
HOW CAN YOUNG PEOPLE GET INTO A CAREER LIKE YOURS?

An academic career in this area entails doing an undergraduate degree in a subject like computer science, psychology or medicine. You'd need to do a masters and then apply for a PhD to do your doctoral training. At the University of Nottingham, we have a centre for doctorial training and we welcome candidates from psychology, social care, economics and the social sciences who are interested in understanding the impact of digital technology on human behaviour. We have plenty of room for students who are passionate and dynamic and who have a vision for what they want society to be like in 30 years' time.

\section{HOW DO I KNOW IF}

RESEARCH IS FOR ME?

It's easy to Romanticise what research is going to be like. The best way to find out is to get involved by doing small projects whenever you can. Some people do a project and realise that research is not for them. But others discover that it's what they want to do for the rest of their lives.

\section{ELVIRA'S TOP TIPS FOR STUDENTS}

1 Build resilience to cope with setbacks

2 Don't be afraid of failure and don't give up

3 Try small projects to see if you enjoy

4 Develop interpersonal skills to talk to researchers with different backgrounds

5 Work hard and persevere

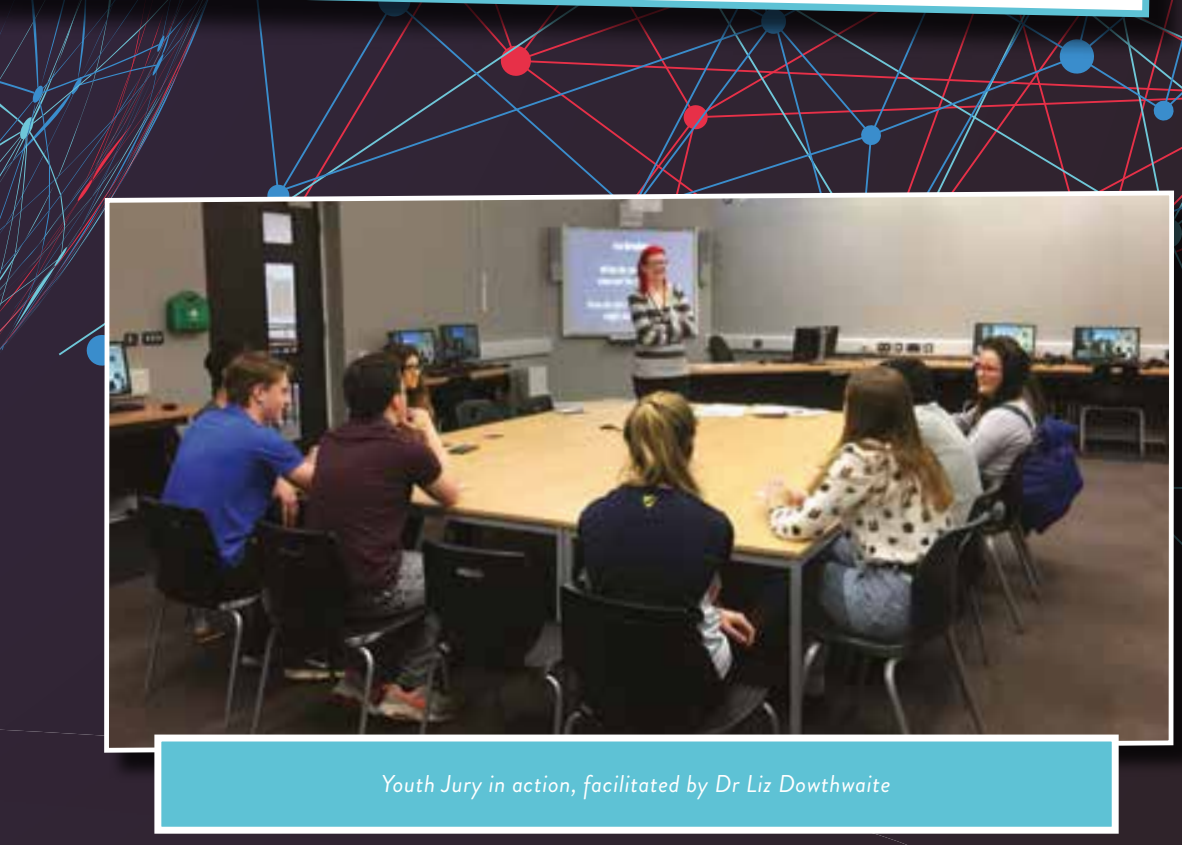




\section{0 DIGITAL TECHNOLOGY AND MENTAL HEALTH WITH DR ELVIRA PEREZ}

\section{VALLEJOS}

\section{Q \\ TALKING POINTS}

1. What is an algorithm? (See the first part of the article)

2. Can you think of three things algorithms are good for?

3. What are the possible dangers of algorithms? How do you feel about machines deciding what you should see? (See Are algorithms a good thing?)

4. Name two things the ReEnTrust project is doing to help us trust websites and social media. What will be the ultimate outcome of Elvira's research? (See How will ReEnTrust help?)

5. With a friend, work out roughly how many hours each of you spends on social media every day. How about every week? Do you think it's too much, and why?

\section{How might the use of social media affect your mental} health - for better or worse? (See About digital technology and mental health)

7. Use a TV or film app to watch something it recommends for you. Did you enjoy it, and why do you think the algorithm recommended it?

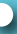
ACIIVITIES YOU CAN DO AI SCHOOI, COLIEGE OR AT HOME

\section{PLAY FAIRNESS TOP TRUMPS}

Download the Fairness Toolkit from https://unbias.wp.horizon.ac.uk/ fairness-toolkit/ and print out the cards and leaflet.

Play Top Trumps: pick an Example card and place it face up. Example cards include "Fake news?", "Hate speech and cyberbullying",

"Personalisation" and "Gender bias". Now take the Data, Rights, Factors and Values cards, shuffle them and deal them out amongst the players. In turn, each player places one of their cards on top of the Example if they can explain why the particular issue is relevant.

The winner is the player who's added the most cards.

\section{TEST YOUR SKILLS AT SPOTTING FAKE NEWS}

Go to the CBBC website and try the quiz: "Real or Fake". Some of the stories are real and some are made up - how many did you get right? If you got any wrong, why do you think you were fooled?

https://www.bbc.co.uk/cbbc/quizzes/real-or-fake-news-quiz

3. Watch a snippet of this YouTube video of former US President Barack Obama and notice how it's split in two. On the right-hand side is a very realistic computer model of Obama's head, which was trained to speak his words. What would be the danger of making a computer model of another politician and giving them words they didn't say? How could you tell if it was really them?

https://www.youtube.com/watch?v=9Yq67CjDqvw

4. Can you think of any examples in recent politics where algorithms could have created bias? 


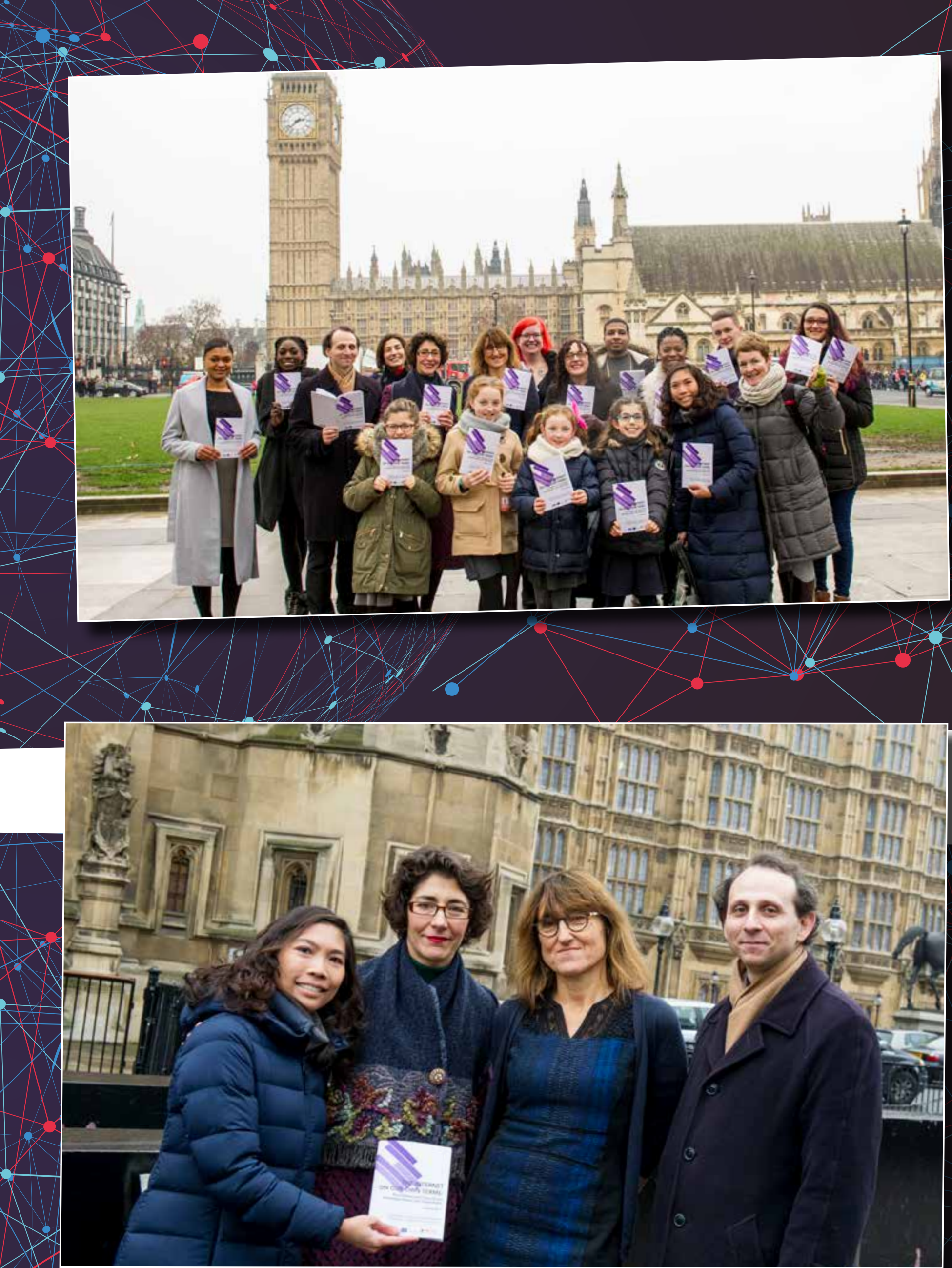




\section{futurum}

Know what you want to be
WWW.FUTURUMCAREERS.COM

TEL: +44 1179099150

EMAIL: INFO@FUTURUMCAREERS.COM

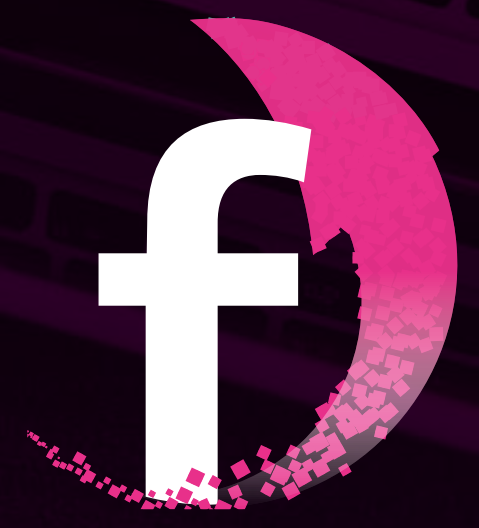

